\title{
CONHECIMENTOS E PRÁTICAS DO AUXILIAR DE ENFERMAGEM EM SALA DE IMUNIZAÇÃO
}

Lucas Rodrigues Feitosa ${ }^{1}$, Jullyanne Alexandre Feitosa ${ }^{1}$, Maria Wanderleya de Lavor Coriolano ${ }^{2}$

RESUMO: Este estudo, de abordagem qualitativa, teve como objetivo analisar conhecimentos e práticas do auxiliar de enfermagem em sala de imunização, considerando seu papel fundamental na Atenção Básica. Os instrumentos para coleta de dados foram a entrevista e a observação não participante, aplicados a 10 auxiliares de enfermagem. A análise de dados foi realizada conforme a Análise de Conteúdo de Bardin, com elaboração de cinco categorias temáticas: Contaminação com materiais da sala de vacinas; Descarte do lixo produzido na sala de vacinação; Educação permanente dos profissionais da sala de imunização; Orientações prestadas às mães; e Relação enfermeiro e auxiliar de enfermagem. A mecanicidade do trabalho, capacitação deficiente, falta de orientações à clientela quanto à finalidade e reações adversas foram alguns problemas identificados. Diante dos resultados, recomenda-se maior investimento na educação permanente destes profissionais aliando o conhecimento científico ao cotidiano do trabalho para uma atuação mais fortalecida e humanizada. PALAVRAS-CHAVE: Imunização; Educação em enfermagem; Enfermagem em saúde comunitária; Atenção primária à saúde.

\section{KNOWLEDGE AND PRACTICES OF NURSING AUXILIARY AT THE IMMUNIZATION ROOM}

\begin{abstract}
This study uses a qualitative approach and aimed to examine knowledge and practices of the nursing auxiliary in the immunization room considering their role in Primary Care. The instruments for data collection were interviews and non-participant observation, applied to 10 nursing auxiliaries. Data analysis was performed according to Bardin's content analysis, including the development of five thematic categories: Contamination with materials in the room of vaccines; Dispose of garbage produced in the vaccination room, Continuing education of professionals at the immunization room; guidelines provided to mothers; Nurses and nursing auxiliaries relationship. Highlighted problems: The mechanicalness of work, lack of training, lack of guidance to customers on the purpose of immunization and side effects were some problems. Greater investment in continuing education of professionals combining scientific knowledge to daily work for a more strengthened and humanized is recommended.
\end{abstract}

KEYWORDS: Immunization; Nursing Education; Community health nursing; Primary healthcare.

\section{CONOCIMIENTOS Y PRÁCTICAS DEL AUXILIAR DE ENFERMERÍA EN SALA DE INMUNIZACIÓN}

RESUMEN: Este estudio, de abordaje cualitativo, tuvo como objetivo analizar conocimientos y prácticas del auxiliar de enfermería en sala de imunización, considerando su papel fundamental en la Atención Básica. Los instrumentos para recoger datos fueron la entrevista y la observación no participante, aplicados a 10 auxiliares de enfermería. El análisis de datos fue realizado de acuerdo al Análisis de Contenido de Bardin, con elaboración de cinco categorías temáticas: Contaminación con materiales de la sala de vacunas; Descarte de la basura producida en la sala de vacunación; Educación permanente de los profesionales de la sala de inmunización; Orientaciones a las madres; Relación enfermero y auxiliar de enfermería. El hecho del trabajo ser mecánico, la capacitación deficiente, falta de orientaciones al cliente cuanto a la finalidad y reacciones secundarias fueron algunos problemas identificados. Delante de los resultados, se aconseja mayor inversión en la educación permanente de eses profesionales, aliando conocimiento científico al cotidiano del trabajo para una actuación más fuerte y hunanizada.

PALABRAS CLAVE: Inmunización; Educación en enfermería; Enfermería en salud comunitaria; Atención primaria a la salud.

\footnotetext{
${ }^{1}$ Acadêmico de Enfermagem da Universidade Regional do Cariri-URCA.

${ }^{2}$ Enfermeira. Doutoranda em Saúde da Criança e do Adolescente pela Universidade Federal de Pernambuco-UFPB.
}

Autor correspondente:

Maria Wanderleya de Lavor Coriolano.

Universidade Federal de Pernambuco

R. Rodrigues Ferreira, 45 - 50810-020 - Várzea-PB-Brasil Recebido: 25/02/10

Email: wandenf@yahoo.com.br

Aprovado: 09/11/10 


\section{INTRODUÇÃO}

A imunização previne várias doenças transmissíveis em crianças, principalmente no primeiro ano de vida, e constitui-se em importante medida para a redução da mortalidade infantil. Em 1974, a Organização Mundial de Saúde (OMS) criou o Programa Ampliado de Imunização (PAI) com o objetivo de, até 1990, disponibilizar às crianças de todo o mundo vacinas para o controle de algumas doenças, como difteria, coqueluche, tétano, paralisia infantil, tuberculose e sarampo ${ }^{(1)}$.

No Brasil, o Programa foi regulamentado, suas normas organizadas e competências definidas em 1975. Hoje, são metas operacionais: vacinar 100\% dos menores de um ano com todas as vacinas indicadas para o primeiro ano de vida: Bacilo de Calmette e Guérin (BCG), tríplice viral, poliomielite, hepatite B e tetravalente; bem como vacinar $100 \%$ das crianças menores de cinco anos de idade que não tenham sido vacinadas ou que não tenham completado o esquema básico no primeiro ano de $\operatorname{vida}^{(1)}$.

Também é meta do PAI realizar cobertura vacinal eficiente e ativa, tanto em âmbito nacional como nos estados. Os resultados obtidos por essas coberturas são satisfatórios, principalmente no grupo infantil, fazendo com que a incidência de doenças passíveis de imunização sofram redução significativa ${ }^{(2)}$.

Para que o Programa alcance as metas estabelecidas com a eficácia desejada é essencial que se monitore e avalie o desenvolvimento das atividades relativas à vacinação nos diversos níveis. Faz-se necessário identificar as dificuldades enfrentadas pela equipe de saúde, os problemas relacionados à estrutura física e à assistência prestada aos usuários dos serviços, principalmente no âmbito mais descentralizado do sistema de saúde-Atenção Básica ${ }^{(3)}$.

A sala de vacina, local para administração de vacinas na Unidade de Saúde da Família (USF), deve estar devidamente limpa e organizada, prevenindo infecções e proporcionando ao usuário assistência segura e de qualidade. Cabe ao enfermeiro planejar, organizar, supervisionar e executar as atividades de enfermagem referentes à imunização na Atenção Básica, e fazer parte da elaboração dos programas multiprofissionais de saúde pública, direcionados à coletividade ${ }^{(3)}$. São também atribuições do enfermeiro a avaliação do processo, com desenvolvimento de um trabalho de monitoramento e averiguação de resultados.

$\mathrm{O}$ auxiliar de enfermagem, por sua vez, exe- cuta a maior parte das atividades na sala de vacina, as quais compreendem organização do ambiente, administração de imunobiológicos, orientação à clientela sobre o tipo de vacina, reações esperadas e reações adversas, descarte dos materiais utilizados, organização do arquivo, registro das vacinas no cartão da criança, nos mapas e no arquivo ${ }^{(3-6)}$. Estas atividades requerem conhecimentos e práticas que garantam a qualidade e efetividade da imunização para o paciente/ família.

Neste contexto, o presente estudo se propôs a responder a seguinte pergunta: Os conhecimentos e práticas do auxiliar de enfermagem em sala de imunização na Atenção Básica no Município de Iguatu/Ceará estão condizentes com as diretrizes do Ministério da Saúde?

A relevância da pesquisa centra-se no objetivo de conhecer a atuação do auxiliar de enfermagem em sala de vacinação, visando fornecer subsídios para atividades educativas, com vistas a aperfeiçoar as práticas relacionadas à imunização.

\section{METODOLOGIA}

Trata-se de uma pesquisa descritiva e exploratória com abordagem qualitativa, que para alcançar o objetivo utilizou como instrumento uma entrevista semiestruturada, seguida de um roteiro de observação não participante, procurando desvendar as crenças, valores e subjetividades dos sujeitos entrevistados ${ }^{(7)}$.

A pesquisa foi realizada em Iguatu/Ceará, no período de agosto a novembro de 2009. A população do município, de acordo com dados do Instituto Brasileiro de Geografia Estatística (IBGE), é de 92.260 habitantes ${ }^{(8)}$.

A população-alvo do estudo foram os auxiliares de enfermagem que trabalham na Estratégia Saúde da Família (ESF) do município, o qual conta com 25 Equipes de Saúde da Família e cada equipe possui dois auxiliares de enfermagem, totalizando 50. Destes, foram selecionados aqueles que trabalhavam na Zona Urbana com, no mínimo, um ano de trabalho na equipe e que aceitasse participar voluntariamente da pesquisa. Como critério para delimitação da amostra utilizou-se a saturação dos dados.

Para a realização da pesquisa foi realizada uma entrevista semiestruturada. A entrevista foi gravada e transcrita na íntegra, após o consentimento dos participantes por meio do Termo de Consentimento Livre e Esclarecido (TCLE). 
A entrevista seguiu questões norteadoras que serviram de guia no processo de coleta das informações; a observação não participante teve por objetivo perceber aspectos da realidade estudada, utilizando os sentidos para ver, ouvir e examinar fatos ou fenômenos. O registro ocorreu no momento da observação.

A técnica utilizada para a análise dos dados foi a Análise de Conteúdo, na qual as falas dos entrevistados foram organizadas em categorias temáticas ${ }^{(9)}$.

A pesquisa respeitou a Resolução 196/96, do Conselho Nacional de Saúde, que dita as diretrizes e normas a serem respeitadas no que concerne a pesquisas envolvendo seres humanos, considerando o consentimento dos participantes, respeitando o anonimato da população envolvida e o sigilo das informações obtidas. O estudo recebeu parecer favorável do Comitê de Ética em Pesquisa da Faculdade de Medicina de Juazeiro do Norte (FMJ), n. 2009 0454 ${ }^{(10)}$. Para garantia do anonimato, as participantes foram denominadas com pseudônimos de deusas gregas.

\section{RESULTADOS}

Foram entrevistadas 10 auxiliares de enfermagem das equipes de Saúde da Família, todas do sexo feminino, com tempo de trabalho de 1 a 5 anos $^{(3)}$, de 5 a 15 anos $^{(5)}$ e com mais de 15 anos ${ }^{(2)}$. Quando indagadas sobre a realização de cursos de atualização na área de imunização, apenas duas informantes disseram já ter participado de atualizações. Como se trata de um tema em constante modificação e pertinente à atuação diária dos auxiliares de enfermagem, torna-se relevante a educação permanente destes profissionais sobre temáticas relacionadas ao exercício do seu trabalho, proporcionando uma melhor atuação junto à clientela.

Os depoimentos obtidos na realização das entrevistas subsidiaram a construção das cinco categorias temáticas, apresentadas a seguir.

\section{Temática 1: Contaminação com materiais na sala de vacina}

A sala de vacinação, apesar de ser um local de promoção à saúde, oferece riscos aos profissionais de enfermagem, em consequência da exposição constante aos resíduos contaminados; aos imunobiológicos, que trazem em sua composição determinadas classes de vírus e bactérias; e a fluidos orgânicos que podem afetar sua saúde.

A variedade de riscos existentes na sala de vacinação e a rotinização do trabalho, levam o auxiliar de enfermagem a agir de forma contrária ao recomendado, como evidencia-se nas falas abaixo:

Não. Eu nunca pensei nessa possibilidade, né? E nunca foi me repassado [pela enfermeira] o que fazer. (Atena)

Sim. Já me furei sim, só que eu me furei antes [da aplicação] [...]. Lavei imediatamente com água e sabão e depois coloquei álcool. (Astarte)

Sim. As vacinas. Eu procurei porque foi no olho. Procurei o oftalmologista, mas não teve maiores consequências, não. Foi com a vacina BCG. (Artêmis)

Sim. Eu já me contaminei com injeção [vacina], quando eu fui aplicar numa pessoa eu me furei. Eu, sinceramente, não fiz nada. (Hera)

Sim. Eu procurei o Hospital Regional. Fui orientada pela enfermeira que fez a campanha de vacina. Eu tava fazendo a vacina e me contaminei. (Héstia)

Não apenas na Unidade de Saúde da Família, mas no trabalho do ambiente hospitalar, os auxiliares de enfermagem são acometidos frequentemente em acidentes com materiais perfurocortantes.

Pode-se perceber, também, na fala a seguir, a ausência de supervisão diária no setor, não se conhecendo, assim os acidentes ocorridos com o profissional durante o serviço diário.

Sim. Uma vez eu fui abrir uma tri-viral e entrou ar no frasco [...] ela explodiu um pouquinho e pegou nos meus olhos. Lavei com água em abundância e passei um sabãozinho nos olhos e no rosto. (Minerva)

\section{Temática 2: Descarte do lixo produzido na sala de vacinação}

Quando questionadas sobre o acondicionamento do lixo da sala de vacina, elas deram seguintes depoimentos:

As vacinas são colocadas em um recipiente lacrado e identificado como material contaminado [...] e as seringas são colocadas junto com a embalagem das vacinas em um descartex. E quando não temos o "descartex", é improvisado com uma caixa de pa- 
pelão. (Atena)

As seringas são jogadas na caixinha no cartete [descartex], e as vacinas a gente recolhe numa lata pra levar pra secretaria [Secretaria de Saúde do Município] pra ser queimada. (Afrodite)

Os papeis das seringas a gente coloca no lixo comum, né? E os imunobiológicos não pode ser jogado no lixo comum. É colocado num recipiente, e esse tem que ser esterilizado na estufa, pra ser levado pelo carro da coleta. Coloca na estufa e depois pega a latinha e coloca pro carro da coleta levar. (Héstia)

Nos discursos das auxiliares de enfermagem percebe-se que o descarte do lixo da sala de vacina, e em particular os imunobiológicos que são compostos por vírus mortos ou inativados (pólio e tri-viral) não recebem o devido tratamento inativação, sendo desprezados sem qualquer procedimento.

Apenas uma auxiliar de enfermagem mencionou realizar a descontaminação dos imunobiológicos na estufa, sendo necessária a incorporação de mais conhecimentos para o descarte adequado do lixo produzido na sala de vacinas.

Tematica 3: Educação Permanente dos profissionais da sala de vacinação

Quando abordada esta temática, verificou-se que não há cursos periódicos de atualização sobre o manuseio de vacinas na rotina das Equipes de Saúde da Família e os trabalhadores entrevistados têm pouco tempo para tirar dúvidas com o supervisor da unidade (Enfermeiro) e com acadêmicos que realizam estágios no serviço.

Os relatos a seguir expressam essas situações:

Não. Até agora eu não recebi nenhuma orientação sobre mudança da enfermeira da unidade. Alguma coisa que eu vi de mudança, foi com pessoas que estavam estudando aqui: acadêmicos [...]. (Atena)

Sim. Ela [a enfermeira] sempre vai na sala, olha como a gente tá trabalhando, e orienta é [...]. Da geladeira que ela [a enfermeira] sempre olha se tá em ordem é [...] A maneira que a gente tá vacinando [...]. (Astarte)

Não. Não muito, não por ela [a enfermeira]! Tá entendendo? É questão mesmo da [...] de lá mesmo [Se- cretaria de Saúde]. Por que são poucas as alterações, e quando têm, a gente fica sabendo até por outras pessoas. E no tempo que eu tô aqui eu só tive uma vez reunião sobre vacina [...]. (Artêmis)

Não. Já houve um curso, né? No SENAC, de atualização, e elas [enfermeiras] mandam a gente ir, né? Pra gente se atualizar, né? É muito importante, porque a cada dia que passa as coisas vão mudando, né? A forma de você fazer as coisas vai mudando a cada dia, né? O método vai mudando [...]. (Hera)

Verifica-se, assim, que a Educação Permanente dos trabalhadores do Sistema Único de Saúde (SUS) de nível médio não tem recebido a devida atenção por parte dos gestores e dos profissionais de nível superior. Estes possuem como atribuição a educação permanente dos auxiliares de enfermagem e esta pode ser uma ferramenta de grande relevância para o trabalho profissional na sala de vacina.

\section{Temática 4: Orientações prestadas às mães}

Nas falas a seguir, as auxiliares de enfermagem afirmaram prestar orientações às mães no que diz respeito às vacinas que seriam administradas em seus filhos, enfocando a finalidade, os efeitos adversos, os cuidados pós-vacinais e o retorno ao posto de saúde para nova vacinação. Porém, no ato da observação, foi constatada contradição entre as falas e as ações executadas na rotina do serviço de saúde, sendo evidenciado que auxiliares orientam as mães apenas quanto aos cuidados pós-vacinais e retorno ao posto de saúde:

Sim. Antes, quando a criança chega, eu já digo [à mãe] aonde é que eu vou fazer a vacina, pra que serve e qual é a medicação que ela [a criança] deve tomar. Um paracetamol, que é orientação da enfermeira, ai eu falo pra ela [a mãe] que dê paracetamol, ou alguma coisa por causa da febre. (Astarte)

Sim. Questões de cartão de vacina, de calendário de vacina, o mês a data pra ta retornando, a gente anota já a data pra ficar certo a data pra ela [a mãe] voltar da vacina. (Artêmis)

No que diz respeito às orientações às mães, as auxiliares relatam ser importante orientar, tendo em vista a carência de informações pelo cuidador (mãe) relativas à imunização. Elas afirmam, também, que a 
mãe se tranquiliza com as informações e não procura o posto de saúde para esclarecimentos sobre as reações que poderão ocorrer.

Sim. Acho por que algumas mães têm alguma orientação, mas muitas mães são totalmente leigas pra esse tipo de coisa, né? Então, se a gente têm alguma informação, a gente deve passar pras mães. (Atena)

Sim, com certeza, porque evita dela voltar depois, achando que o filho tá doente ou alguma coisa do tipo, não sabendo que aquilo é apenas uma reação da vacina. (Métis)

\section{Temática 5: Relação Enfermeiro e Auxiliar de Enfermagem}

Nas falas que seguem é possível perceber a importância que os auxiliares vêem nesse espaço para esclarecer suas dúvidas. Elas citam o enfermeiro como um profissional que possui um grau de formação superior, preparado para orientar e esclarecer sua equipe, fazendo com que a assistência se torne cada vez mais qualificada:

Sim. Sempre que surgiu dúvida e eu fui procurar, ela [enfermeira] atendeu. E a gente se relaciona muito bem. Acho sim, até porque o enfermeiro já têm um nivel de conhecimento mais elevado, então têm que ter esse relacionamento, né? (Atena)

Qualquer dúvida que eu tenho eu procuro ela [enfermeira], eu não faço nada em dúvida. Pois a gente tá lidando com menor de ano e têm que preservar a integridade física. Por ser bem pequenininho, o organismo ainda não tá bem formado, e tem que ter cuidado, a via de administração da vacina, que reação vai ter, tudo isso a gente passa pra mãezinha. (Minerva)

Nos relatos das auxiliares de enfermagem, observa-se que a interação entre o auxiliar de enfermagem e o enfermeiro do serviço assume um caráter informal, tendo em vista que, diante de dúvidas relacionadas à sua atuação, o auxiliar de enfermagem esclarece suas dúvidas. Entretanto, no que se refere à educação permanente em serviço, o enfermeiro não tem assumido esta função na Atenção Básica, sendo necessária maior apropriação de conhecimentos do auxiliar, a partir desta importante ferramenta que é a educação em serviço.

\section{DISCUSSÃO}

Os exercícios de atividades manuais que visam à produtividade estão vinculados a fatores que transformam beneficamente o indivíduo e o meio em que ele está inserido, mas também leva a situações de risco que causam injúrias aos trabalhadores, desencadeadas pelas condições de trabalho e/ou pelo modo como ele é organizado. O trabalho no setor saúde, por exemplo, é executado em locais onde existe constante exposição a fatores de risco de diversas ordens, que prejudicam aqueles que ali exercem suas atividades ${ }^{(11)}$.

$\mathrm{O}$ escasso conhecimento dos auxiliares de enfermagem sobre as formas de contaminação na sala de vacinação, a ausência de práticas educativas permanentes, a falta de equipamentos de proteção individual, como luvas e óculos, bem como a escassa noção sobre biossegurança, ressaltam a falta de orientação pelo supervisor da unidade, lacunas que potencializam os fatores de risco para contaminação.

Os auxiliares de enfermagem constituem o principal grupo a sofrer acidentes no contexto do trabalho em saúde. Estudo realizado em hospital de Fortaleza/Ceará encontrou que, dentre 42 fichas de notificação de acidente com material perfurocortante, $54,8 \%$ pertenciam a auxiliares de enfermagem, fato atribuído a esta categoria ser a mais numerosa dentre os profissionais de enfermagem e prestar assistência direta ao paciente ${ }^{(12)}$.

É importante fazer menção ao despreparo dos profissionais médicos e enfermeiros que, na maioria das vezes, não dão importância ao evento, ou não oferecem condutas adequadas de atendimento quando procurados, não indicando a quimioprofilaxia.

Estudos têm sido desenvolvidos com o intuito de demonstrar a eficácia de tratamentos prescritos a pacientes com diversos diagnósticos, tendo o olhar voltado para o comportamento do cliente, isto é, para o seguimento exato do tratamento proposto. No entanto, são poucas as publicações internacionais e nacionais sobre a adesão à quimioprofilaxia em trabalhadores da saúde pós-exposição a material biológico ${ }^{(13)}$.

$\mathrm{O}$ descarte do resíduo produzido na sala de vacinas deve ser efetuado de maneira correta, para que não comprometa a saúde do auxiliar de enfermagem, de quem coleta o material, do meio ambiente e da população em geral. Várias pessoas entram diariamente em contato com o lixo produzido na sala de vacinas, 
podendo assim sofrer contaminação caso não sejam tomados os devidos cuidados.

No Brasil, embora os acidentes de trabalho com exposição ao material biológico sejam frequentes, não existe ainda um real diagnóstico do número de trabalhadores acidentados e das consequências causadas por essas injúrias, o que tem dificultado o planejamento e a adoção de medidas preventivas ${ }^{(14)}$.

A proposta de educação permanente foi desenvolvida como estratégia para alcançar o desenvolvimento da relação entre o trabalho e a educação. Ela parte do pressuposto de que o conhecimento se origina na identificação das necessidades e na busca de solução para os problemas encontrados. Para isso, são válidos tanto o conhecimento científico como o popular, e a atividade do trabalhador pode ser o ponto de partida de seu saber real, determinando, desta maneira, sua aprendizagem ${ }^{(15)}$.

No caso dos auxiliares de enfermagem, são observadas poucas iniciativas de cursos de atualização para estes profissionais, o que pode ser um importante entrave para modificação de práticas e rotinas instituídas. Esse fato pode prejudicar a qualidade da assistência prestada à clientela, já que os auxiliares são os responsáveis diretos pela prestação de muitos serviços, como a aplicação de vacinas, organização da sala de vacinas, dispensação de medicamentos, injeções, realização de curativos, atividades de cunho essencialmente técnico, mas que exigem um conhecimento científico apropriado.

Além da velocidade com que conhecimentos e saberes tecnológicos se renovam na área da saúde, a distribuição de profissionais e de serviços - segundo o princípio da acessibilidade para o conjunto da população o mais próximo de sua moradia ou de onde procuram por atendimento - faz com que se torne muito complexa a atualização permanente dos trabalhadores. Torna-se crucial o desenvolvimento de recursos tecnológicos dirigidos pela noção de aprender a aprender, de trabalhar em equipe, de construir cotidianos de aprendizagem individual, coletiva e institucional ${ }^{(16)}$.

O princípio de se educar para saúde e para o ambiente parte da hipótese de que vários problemas de saúde são resultantes da precária situação educacional da população, carecendo, portanto, de medidas "corretivas" e/ou educativas ${ }^{(17)}$.

Orientar é uma ação importante no que diz respeito à melhoria da qualidade do serviço de saúde. Recebendo orientações do auxiliar de enfermagem sobre a finalidade da vacina, possíveis efeitos adversos e cuidados pós-vacinais, a mãe torna-se melhor preparada para atender a criança em caso de intercorrências.

Nas ações da equipe de Saúde da Família é importante que haja um intercâmbio entre o enfermeiro e o auxiliar de enfermagem, no que diz respeito ao esclarecimento de dúvidas que surjam no trabalho. $\mathrm{O}$ enfermeiro do serviço é o responsável pela equipe, cabendo a ele supervisionar o auxiliar de enfermagem, orientando para que realize a atividade profissional de forma ideal, sem causar danos à saúde da clientela ${ }^{(18)}$.

Neste processo de relacionamento, a comunicação constitui um instrumento imprescindível utilizado pelos profissionais de enfermagem como um meio para realizar suas tarefas em equipe, haja vista que este trabalho fundamenta-se na interação coletiva entre os seus integrantes ${ }^{(18)}$.

\section{CONSIDERAÇÕES FINAIS}

Pôde-se perceber a mecanicidade do auxiliar de enfermagem na sala de vacinação, bem como a falta de treinamento, capacitação e reflexão, potencialmente prejudicando a qualidade do serviço prestado. Paralelamente ao baixo conhecimento, destaca-se importante lacuna na orientação à clientela.

Diante dos resultados apresentados, recomenda-se um maior investimento na educação permanente destes profissionais, aliando o conhecimento científico ao cotidiano do trabalho para uma atuação mais fortalecida e humanizada.

\section{REFERÊNCIAS}

1. Santos DM, Dubeux LS, Frias PG. Avaliação normativa da ação programática imunização nas equipes de saúde da família do município de Olinda, Estado de Pernambuco, Brasil, em 2003. Epidemiol Serv Saúde. 2006;15(3):29-35.

2. Mota E. Inquérito domiciliar de cobertura vacinal: a perspectiva do estudo das desigualdades sociais no acesso à imunização básica infantil. Rev Bras Epidemiol. 2008;11(3):125-8.

3. Rosa IM, Morishita A, Pedrinho LR. Percepção de auxiliares de enfermagem sobre sua atuação na sala de vacina. Arq APADEC. 2004;8(2):1414-9.

4. Santos RM, Tereza MCSF, CandiottiZMC. Circunstâncias da oficialização do curso de auxiliar de enfermagem no Brasil: estudando as entrelinhas da lei 775/49. Rev LatinoAm Enfermagem. 2002;10(4):561-70. 
5. Brasil. Lei n. 7.498, de 25 de junho de 1986. Dispõe sobre a Regulamentação do Exercício da Enfermagem, e dá outras providências. Diário Oficial da República Federativa do Brasil, Brasília, 26 jun. 1986. Seção 1:1.

6. Assad LG, Viana LO. Formas de aprender na dimensão prática na atuação do enfermeiro assistencial. Rev Bras Enferm. 2005;58(5):86-91.

7. Minayo MCS. O desafio do conhecimento: pesquisa qualitativa em saúde. São Paulo: Hucitec; 2000.

8. Ministério da Saúde (BR). Secretaria de Vigilância em Saúde. Manual de vigilância epidemiológica de eventos adversos pós-vacinação. Brasília: 2007.

9. Bardin L. Análise de conteúdo. Lisboa: Edições 70; 1977.

10. Ministério da Saúde (BR). Conselho Nacional de Saúde. Diretrizes e normas regulamentadoras de pesquisa envolvendo seres humanos. Resolução n. 196, de 10 de outubro de 1996. Brasília; 1996.

11. Galon T, Robazzi MLCC, Marziale MHP. Acidentes de trabalho com material biológico em hospital universitário de São Paulo. Rev Eletron Enferm. [Internet] 2008;10(3) [acesso em $15 \mathrm{dez} 2009$ ]. Disponível: http://tiny.cc/1vz2d

12. Paulino DCR, Lopes MVO, Rolim ILTP. Biossegurança e acidentes de trabalho com perfuro-cortantes entre os profissionais de enfermagem de Hospital Universitário de Fortaleza-CE. Cogitare Enferm. 2008;13(4):507-13.

13. Almeida CAF, Benatti MCC. Exposições ocupacionais por fluidos corpóreos entre trabalhadores da saúde e sua adesão à quimioprofilaxia. Rev Esc Enferm USP. 2007;41(1): 120-6.

14. Marziale MHP, Silva EJ, Haas, VH, Robazzi MLCC. Acidentes com material biológico em hospital da rede de prevenção de acidentes do trabalho - REPAT. Rev Bras Saúde Ocup. 2007;32(115):109-19.

15. Lopes SRS, Piovesan ETA, Melo LO. Potencialidades da educação permanente para a transformação das práticas de saúde. Com Ciências Saúde. 2007;18(2):147-55.

16. Ceccim RB. Educação permanente em saúde: descentralização e disseminação da capacidade pedagógica na saúde. Ciênc Saúde Colet. 2005;10(4): 975-86.

17. Gazzinelli MF, Gazzinelli A, Reis DC, Penna CMM.
Educação em saúde: conhecimentos, representações sociais e experiências da doença. Cad Saúde Pública. 2005;18(1):120-6.

18. Wagner LR, Thofehrn MB, Amestoy SC, Porto AR, Arrieira ACO. Relações interpessoais no trabalho: percepção de técnicos e auxiliares de enfermagem. Cogitare Enferm. 2009; 14(1):107-13. 